\title{
Parcerias entre o setor público e o privado em escolas estaduais paulistas e o trabalho do professor: alguns dados para reflexão
}

\author{
Alda Junqueira Marin ${ }^{*}$, Marieta Gouvêa de Oliveira Penna ${ }^{* *}$
}

Resumo: Apresentam-se neste artigo reflexôes sobre o desenvolvimento de açóes em escolas públicas por meio de parcerias entre o setor público e o privado, a partir de pesquisa empírica que visou analisar os efeitos produzidos na dinâmica escolar, especificamente no que diz respeito ao trabalho do professor.

Palavras-chave: políticas públicas educacionais; parcerias entre o setor público e o privado; docência.

Partnerships between the public and the private sector in São Paulo state schools and the teacher's work: some facts to ponder

Abstract: This paper presents reflections on the development of activities in public schools through partnerships between the public and private sectors, based on empirical research which aimed to analyze the effects on school dynamics, specifically in what regards the teacher's work.

Key words: public policies in education, partnerships between the public and private sectors, teaching.

\section{Introdução}

O desenvolvimento de ações em escolas públicas, por meio de parcerias firmadas entre o setor público e o privado, com o objetivo declarado de melhorar a qualidade do ensino, necessita ser compreendido como parte de um conjunto de proposiçóes que expressam os novos rumos tomados pelas açóes políticas educacionais na atualidade. Assim, por um lado, faz-se necessário compreender essas ações inseridas em

Professora do Departamento de Fundamentos da Educação da Pontifícia Universidade Católica de São Paulo, Brasil. aldamarin@pucsp.br

** Professora do Departamento de Educação da Escola de Filosofia, Letras e Ciências Humanas da Universidade Federal de São Paulo, Brasil.marieta.penna@yahoo.com.br 
discurso hegemônico neoliberal, que se impóe como evidente e como a melhor e a mais eficiente saída para a resolução dos problemas educacionais na atualidade, e também para a promoção da qualidade na educação. Dois itens do texto abordarão tais aspectos. Por outro, faz-se necessário ir às escolas para compreender os efeitos produzidos por essas açóes na dinâmica escolar e no trabalho do professor. Este constitui o terceiro bloco de informaçóes.

A investigação aqui apresentada sobre essa temática buscou compreender os efeitos, na dinâmica escolar e no trabalho do professor, decorrentes da parceria entre o setor educacional público e privado, porém não tem a pretensão de analisar o impacto geral dessas açóes. Isso demanda outros tipos de estudos, mais aprofundados e a longo prazo, o que vem sendo perseguido em projeto coletivo institucional. Trata-se, aqui, muito mais do levantamento e da problematizaçáo de questóes que sinalizam para a necessidade de novos estudos e aprofundamentos.

Este artigo, portanto, apresenta parte dos resultados da pesquisa que vem focalizando práticas pedagógicas, sobretudo as dos professores do Ensino Fundamental em escolas públicas de São Paulo. Aqui são apresentados alguns efeitos da parceria firmada entre o setor público e o privado, no que diz respeito aos professores, especialmente no tocante a aspectos do desenvolvimento de hábitos de colaboração e de trabalho em equipe, bem como às condiçóes materiais de seu exercício profissional. Trata-se, portanto, da análise de alguns aspectos dos efeitos percebidos pelos professores em seu dia a dia, em decorrência do estabelecimento de parcerias entre escolas públicas e Organizaçóes Não Governamentais (ONG), a fim de ampliar a compreensão sobre essa faceta das políticas educacionais que incidem sobre as escolas.

\section{Políticas educacionais e privatização do ensino}

As atuais proposiçóes do Estado, no que diz respeito à educação, necessitam ser compreendidas no contexto das políticas econômicas neoliberais, ou seja, inseridas em contexto mais amplo e que se relacionem aos rumos econômicos na atualidade. Assim, as açôes políticas educacionais compóem o quadro de estratégias administrativas adotadas para a gestão pública de serviços sociais, tendo como suporte o ideário neoliberal, sendo permeadas pelas ideias de descentralização, flexibilização e desregulamentação. Para tanto, são propostas e adotadas alteraçóes nas formas de financiamento das políticas sociais, com ênfase no recurso à iniciativa privada (Gentili, 1999).

Para compreender o neoliberalismo como política econômica e as ações de governos a ele relacionadas, para além de considerá-lo como um corpo teórico, é importante destacá-lo relacionado a um conjunto de proposiçóes, por sua vez ligadas a uma cultura de solução de problemas, permeadas pela ideia de eficiência 
e de modernidade na busca de mecanismos mais ágeis para atender às demandas da população, e que promovam cortes de gastos no governo e redução de sua esfera de atuação (Draibe, 1993). Além disso, é importante atentar para a hegemonia desse discurso na atualidade, em que tensionar suas proposiçóes significa ser ultrapassado ou resistente a inovaçóes tidas como imprescindíveis para o bom funcionamento da sociedade. De acordo com Bourdieu (1998), o discurso neoliberal, ao se tornar hegemônico, impóe uma visão de mundo ou um conjunto de pressupostos que se tornam moeda corrente e são tidos como óbvios, transfigurando-se em ideologia.

Segundo Peroni (2007), esse ideário pode ser verificado nas proposiçóes relacionadas à chamada Terceira Via ou Terceiro Setor, que dizem respeito ao repasse, para a sociedade civil, da execução de políticas sociais anteriormente realizadas pelo Estado, ou seja, à reestruturação de programas sociais pela descentralização, focalização (para certos programas e certos grupos) e privatização. Uma das formas de privatização desses serviços é justamente a proposição da distribuição ou contratação de bens e serviços públicos por setores não lucrativos da iniciativa privada (Oliveira, C., 2008). O argumento utilizado para essa distribuição é o da busca de mecanismos mais ágeis e eficientes para atender às demandas da população ou à incapacidade das redes de ensino para o exercício de certas funçôes.

Assim, a fim de compreender as açóes políticas públicas educacionais e o processo de privatização do ensino, não é suficiente questionar o montante de investimentos nesse setor. É preciso compreender, por um lado, que a privatização da escola pública se insere em amplo processo de reestruturação da vida societária nas sociedades capitalistas na contemporaneidade, no qual se destaca "o progressivo desmantelamento do Estado como agência produtora de bens e serviços e como aparelho institucional orientado a garantir e promover os direitos da cidadania" (Gentili, 1999, p. 106). Por outro lado, é preciso compreender as especificidades implicadas nos processos de privatização das escolas públicas, quanto ao fato de responsabilidades públicas serem assumidas por organizaçóes ou entidades privadas. De acordo com esse autor, diferentes possibilidades de privatização do ensino podem ser verificadas, ao levar em consideração tanto o oferecimento desse serviço quanto seu financiamento.

Uma das modalidades de privatização do campo educacional destacada pelo autor é o que ele denomina de "apadrinhamento de escolas como forma de privatização" (Gentili, 1999, p. 116). Trata-se da transferência de determinadas responsabilidades de investimentos em educação, do governo para indivíduos ou empresas, que passam a contribuir financeiramente com instituiçóes escolares, especialmente em aspectos como infraestrutura e equipamentos. Para o autor, esse patrocínio pedagógico é justificado por diferentes argumentos, tais como a necessidade de ajudar o Estado a implantar açôes sociais que minimizem a situação de pobreza e 
desagregaçáo social, a responsabilidade social, ou mesmo argumentos relacionados à melhoria da imagem das empresas envolvidas em açóes solidárias.

Cabe ainda destacar que essas estratégias de privatização dos serviços educacionais, relacionadas à lógica de enxugamento do estado neoliberal em relação a gastos e investimentos sociais, não comprometem a lógica também presente nesse ideário de fortalecimento do Estado, no que diz respeito ao seu poder decisório e de gerenciamento e controle da educação, e que na atualidade ocorre, entre outras formas, por meio de mecanismos de medição e avaliação dos resultados obtidos nas escolas por alunos e professores.

Diante das questóes acima destacadas, importa analisar o que ocorre nas escolas quando da efetivação dessas parcerias, uma vez que, por um lado, se trata de instituição com lógica e cultura específicas, cujas práticas não se alteram com tanta facilidade. Os problemas e as prioridades educacionais não são passíveis de serem submetidos à lógica econômica, se de fato se quer enfrentá-los. Por outro lado, essas parcerias ocorrem num momento em que se intensifica o controle sobre as açóes dos professores, seja por meio de processos de avaliação do desempenho dos alunos e das escolas, seja por meio da adoção de propostas curriculares que normatizam suas práticas em sala de aula. Assim, é relevante atentar para as formas como essas parcerias incidem sobre o trabalho dos professores nas escolas.

\section{Parcerias entre o setor público e o privado em São Paulo}

A Secretaria de Estado da Educaçáo de São Paulo (Seesp) conta, desde 1987, entre seus órgãos vinculados, com a Fundação para o Desenvolvimento da Educação (FDE), responsável por viabilizar a execução das políticas educacionais definidas pela Secretaria, desempenhando papel essencial na gestão da educação. Em sua estrutura organizacional a FDE possui, entre outras, a Gerência de Educação e Cidadania (Geci), que tem por atribuiçáo executar projetos e atividades relacionados ao Programa Parceria/Cooperação Escola, Comunidade e Sociedade Civil, promovendo a articulação da participação da sociedade civil no processo educativo, especialmente por meio de parcerias com o terceiro setor.

Dentre os projetos por ela geridos, está o "Projeto Empresa Educadora", que tem por objetivo incentivar a realização de açóes educacionais a partir de parcerias firmadas entre a Seesp e empresas ou entidades do setor privado. Tal projeto, implantado pela Seesp na gestão do governador Geraldo Alckmin, está regulamentado pela Resolução SE n o 24, de 05/04/05, e diz respeito à realização de investimentos e melhorias nas escolas públicas estaduais paulistas por empresários parceiros ${ }^{1}$.

I. Para consultas ao parecer, acessar: <http://educacao.sp.gov.br/>. Acesso em: 24/08/2009. 
Segundo termos da própria resolução, tem-se a normatização de que a escolha das escolas nas quais se farão investimentos fica a cargo dos empresários e que as açôes realizadas vão desde intervençóes na parte física dos espaços escolares até investimentos no que se denomina capital humano e em materiais de apoio técnico, devendo ser discutidas com a comunidade escolar. Ainda de acordo com a Resoluçáo, é objetivo do Projeto o estímulo ao desenvolvimento da autonomia de gestâo nas escolas e a busca da qualidade do ensino. As açóes desenvolvidas nas escolas por meio de parcerias deverão integrar-se às diretrizes educacionais da Seesp, sendo acompanhadas e avaliadas pelas Diretorias de Ensino - órgãos regionais que compóem a administração da rede no estado de São Paulo.

Pretende-se, assim, promover o fortalecimento da escola pública, com a participação da comunidade escolar na execução das parcerias, além de possibilitar ao setor privado a prática da responsabilidade social. As empresas, após avaliação da FDE, devem contribuir para a otimização de recursos existentes na escola por meio de investimentos tanto na parte física quanto na pedagógica. Segundo dados obtidos no sítio da FDE, não existe um valor mínimo para o investimento, e os recursos são repassados diretamente para a Associação de Pais e Mestres (APM) da escola. Informa-se, ainda, que o Projeto "Empresa Educadora" está crescendo, com aumento de $100 \%$ no número de parcerias entre empresas privadas e unidades da

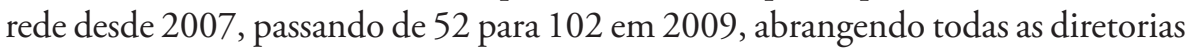
de ensino do estado. Nesse mesmo período, o número de empresários parceiros cresceu, passando de 29 para 67. Após um ano de realização do Projeto, a empresa recebe o selo "Empresa Educadora", outorgado pela Secretaria da Educação do Estado de São Paulo, que permitirá seu reconhecimento como uma instituição ativa e socialmente responsável.

Frente ao exposto, é possível afirmar que a realização de parcerias com o setor privado é ação política de estado adotada pela Seesp para a gestão da educação pública.

\section{No interior da escola}

O procedimento escolhido para a realização desta parte da pesquisa foi a entrevista semiestruturada, com o grupo de professores do Ensino Fundamental I de uma escola pública estadual paulista, na cidade de São Paulo. Em decorrência de solicitação dos professores, foi realizada de forma coletiva, assumindo características de um grupo focal. Neste relato, os professores estão identificados pela letra M seguida de números entre parênteses. A entrevista com os professores teve cerca de uma hora e meia de duração e ocorreu na sala dos professores, durante o horário de trabalho coletivo, a ser cumprido pelo professor da rede pública estadual paulista semanalmente, em sua escola sede. Todos os professores presentes na reuniáo - sete 
no total - tiveram participação. A fim de possibilitar compreensão da percepção dos docentes sobre a parceria e também sobre os efeitos por ela produzidos em suas ações cotidianas e em seu desenvolvimento profissional, os professores foram incentivados a falar sobre questôes como trabalho coletivo, participação nas tomadas de decisão, além de benefícios ou entraves gerados pela parceria em seu trabalho pedagógico. Também foi realizada entrevista com a diretora.

Cabe destacar que nossa presença causou incômodo na escola, pois, no dia da entrevista com os professores, fomos interrogadas por uma representante dos parceiros sobre se tínhamos recebido autorização da empresária para fazer a pesquisa, o que revela a necessidade de estudos que busquem compreender os efeitos causados pelo "apadrinhamento" das escolas, ou seja, como o espaço público tem se tornado, em certos aspectos, um espaço privado dentro do qual os agentes públicos sentem-se, e são, cerceados.

A escolha da escola ocorreu em função de ela ser um estabelecimento central, localizado próximo a uma estação de metrô, o que facilita o acesso, além de contar com açóes desenvolvidas por meio de parceria com uma empresa desde 2005, ou seja, há mais de quatro anos. A escola investigada está situada em regiáo central, mas desvalorizada e, segundo os professores, a maioria dos alunos mora nos cortiços existentes na redondeza, pertencendo a famílias com poucos recursos econômicos e culturais. Apesar da reestruturação do ensino ocorrida na rede estadual paulista em $1998^{2}$, a escola mantinha, na época da pesquisa, os três níveis de ensino, com turmas do Fundamental I funcionando no período da tarde, do Fundamental II no período da manhã e do Ensino Médio, à noite.

De acordo com informaçóes obtidas com os professores, a parceria com a iniciativa privada teve início em 2005, por meio de açóes específicas - que tiveram duração de dois anos - voltadas para a implementação de mudanças na forma como estava organizada a gestão escolar. A intenção era otimizar recursos por meio da introdução de uma administração mais racional, indo ao encontro do ideário neoliberal presente nas reformas educacionais, que pressupóe a adoção de gestão escolar ágil, eficiente e moderna (Oliveira, 2008).

Depois, a empresária passou a proporcionar a limpeza da escola e verbas para festas. Também financiou a montagem de uma sala de artes, de um laboratório de informática, além da reforma da entrada da escola, com a instalação de um portão eletrônico e uma portaria, caracterizando suas açôes em intervençôes para a melhoria das condiçóes físicas do espaço escolar, conforme disposto na Resolução no 24 da Seesp, responsabilizando-se por funçôes que deveriam ser assumidas pelo Estado.

2. Em 1998, o Ensino Fundamental foi organizado em: Ciclo I, da primeira a quarta séries; e Ciclo II, da quinta a oitava séries, com o regime de progressão continuada para os oito anos do Ensino Fundamental. Nesse momento, houve uma separação física dos diferentes segmentos do ensino por escolas. 
Nesse sentido, percebe-se a atuação da parceria com o setor privado nas escolas favorecendo cortes nos gastos públicos com a educação e também a redução da esfera de atuação estatal em alguns aspectos.

Desde 2008, ainda segundo informaçóes obtidas com os professores, ela vem desenvolvendo açóes mais direcionadas a questóes pedagógicas, para o que contratou um Instituto, que passou a oferecer formação para o corpo docente. Em 2008, essa formação incidia sobre todos os professores da escola e ocorria semanalmente, envolvendo os componentes curriculares de Matemática e Português de forma alternada, a cada quinze dias. Além disso, a empresária financiou a montagem de turmas de reforço de aprendizagem, a partir do início do segundo semestre, para alunos de todas as séries que apresentassem dificuldades em Português e em Matemática. Essas açóes dizem respeito, portanto, a investimentos voltados à formação humana, conforme previsto na Resolução no 24 da Seesp, que os considera capital humano, seja em relaçáo aos professores, seja em relação aos alunos.

Em 2009, em decorrência da diminuição dos investimentos feitos pela empresária, a formação restringiu-se aos professores do Fundamental I, em Português e em Matemática, até o recesso de julho. $\mathrm{Na}$ época da realização da pesquisa (junho de 2009), os professores informaram que as açóes de formação seriam suspensas, tendo início novas açôes direcionadas ao reforço no processo de escolarização dos alunos, não mais para todas as séries, mas apenas para as primeiras quatro séries do Fundamental I, para alunos com dificuldades em Português.

$\mathrm{Na}$ entrevista com a diretora, foi possível perceber que as ações desenvolvidas pela empresária eram informadas a ela, mas não eram decididas com ela, contraditoriamente ao que está estipulado na legislação. Entre os objetivos do Projeto "Empresa Educadora" estão o estímulo ao desenvolvimento da autonomia de gestão das escolas e a participaçáo da comunidade interna e externa à escola na tomada de decisóes, o que não ocorria na escola investigada. Segundo a diretora, no mais das vezes, ela não era consultada sobre quais as açóes a serem desenvolvidas pela equipe dos parceiros, mas sim informada sobre elas, o que causava um grande mal-estar.

Apesar de sentir uma intromissão na escola, até mesmo física, uma vez que, segundo ela, causando constrangimentos, sua sala era usada por uma representante da equipe dos parceiros, ela [a diretora] avaliou como boa a realização da parceria, especialmente em função das melhorias nas condiçóes materiais de trabalho. Em relação à assessoria pedagógica, no entanto, pondera que, se por um lado, eles não entendem nada de escola, por outro, o que ela pedia para ser feito não era atendido. A diretora não quis participar de entrevista mais longa e também não permitiu que ela fosse gravada, dando a entender que, por pressão da empresária, uma vez que contestou a parceria, precisou sair de licença, afastando- 
se temporariamente da direção. Com relação a essa questão, cabe destacar que a suposta resistência dos agentes escolares às reformas educacionais, ou mesmo a existência de corporativismo entre eles necessita ser dimensionada ${ }^{3}$. Para tanto, faz-se necessário adentrar nas escolas e investigar as maneiras pelas quais novas deliberaçôes chegam aos agentes educacionais, pois, pelo que foi possível evidenciar, não se trata de resistência, mas de reação a imposições e desconsideraçôes sobre seu fazer cotidiano.

Ao analisar os efeitos das açóes da parceria sobre o trabalho do professor, alguns aspectos puderam ser destacados, como: organização do trabalho, conteúdo da formação continuada, condiçóes materiais, relações entre a escola e a família.

\section{Organização do trabalho}

Com a realização da pesquisa, foi possível verificar que as açóes da parceria incidiam diretamente sobre o trabalho do professor, alterando sua organização e sua rotina. Os professores não foram consultados sobre suas necessidades formativas, nem sobre o uso do horário de trabalho coletivo na escola para as açôes de formação. Segundo eles, as ações da parceria eram totalmente impostas, o que se destaca no depoimento citado abaixo:

Já vinha pronto, ninguém nunca pergunta nada. Nem o que a gente queria, nem se queria... (M3).

Pelo que foi possível detectar, os professores sequer tinham certeza se a formação seria realmente suspensa, se ocorreria mesmo o reforço com os alunos, trocando informaçóes naquele momento. Assim, cotejando esses dados com a proposta de resolução regulamentadora das parcerias, o tão propalado objetivo de estímulo à autonomia da gestão e promoção da participação dos atores escolares nas tomadas de decisão sobre as açôes a serem realizadas na escola, de fato, não ocorria.

Foi possível perceber, também, a descontinuidade das açóes, além de arbitrariedade por parte da empresa parceira, que decidia o que fazer, e fazia. Um dos professores entrevistados levantou essa questão:

Porque a parceria, quando vem pra escola, tinha que fazer um contrato de prestação de serviço, e respeitar ele. E ela precisa receber pelo menos as diretrizes da Diretoria, porque da escola, o projeto da escola, isso ela náo vai ler mesmo... (M7).

É possível identificar nesse depoimento que os professores sequer sabiam da normatização que estipula exatamente isso: deveriam ser acompanhadas e avaliadas

3. Sobre essa questão ver, entre outros, Barreto; Leher (2008). 
pela Diretoria de Ensino, e integrar-se às diretrizes educacionais da Seesp. As açóes eram impostas, não tinham continuidade e, no que diz respeito à formação, do ponto de vista dos professores, estavam gerando uma sobrecarga de trabalho, uma vez que estavam "roubando" horas de trabalho coletivo necessárias para a elaboração de aulas e para a troca de atividades entre eles:

É, estava incomodando... Mas tava incomodando porque as coisas não foram conversadas. Claro que incomoda! Porque ninguém perguntou pra gente se a gente teria tempo de fazer isso em casa. Então, por exemplo, primeira e segunda série tem muita atividade. Todo dia tem muita atividade. E então a gente tinha que levar tudo para casa. E então ficou uma coisa louca!!! E além disso, a gente tinha tarefas, foram poucas, mas tinha tarefas da formação. Nós ficamos muito sobrecarregadas! (M1).

Para eles, essas horas de trabalho coletivo na escola deveriam ser ocupadas com o preparo das aulas, e eles estavam bastante descontentes com o fato de serem obrigados a participar da formação oferecida pela parceria.

O que a M1 está falando a gente percebeu ontem. A gente teve um tempo livre para fazer as nossas coisas, porque não teve mais a formação. E o que a gente fez de coisa ontem!!!' A gente preparou atividade, trocamos ideia, eu troquei com ela, ela me passou as dela, eu passei as minhas... Eu senti que deu pra aproveitar bem o dia (M4).

O fato de os momentos de formação ocuparem as horas disponíveis para o trabalho coletivo na escola, do ponto de vista dos professores, dificultou o estabelecimento do trabalho em equipe, fundamental para organizar o fortalecimento do trabalho pedagógico escolar:

Então, se for pensar na parceria, eu acho que ela não favoreceu o trabalho em grupo, ela favoreceu mais o trabalho individual. E o individual não leva a nada. Se a parceria melhorasse o trabalho do coletivo, ai ela tem valor... (M3).

É aqui que se verifica uma das consequências não esperadas para o exercício da profissão, ou seja, as açôes da parceria vão à direção contrária ao estabelecido pelo discurso veiculado pela Secretaria, qual seja, o da necessidade de trabalho coletivo para discussão, implantação e realização do projeto pedagógico. No entanto, ao considerar o ideário orientador do discurso neoliberal, de estímulo à competitividade e ao individualismo, esse resultado era totalmente esperado, reforçando o já existente. 


\section{Conteúdo da formação continuada}

Os professores também estavam insatisfeitos com o conteúdo das ações de formação que, para eles, eram muito teóricas e distantes de seus problemas cotidianos. Não tivemos acesso ao material utilizado nos momentos de formação, o que demandaria uma pesquisa mais aprofundada. Mas foi possível perceber em seus depoimentos que, nas ações de formação propostas pela parceria, ocorria a desvalorização dos saberes da experiência dos professores e a imposição de novos modelos de atuação:

Todas nós tivemos esse sentimento... Porque você podia fazer a tentativa que fosse, não servia... O que a gente faz, na sala de aula, nunca está certo! Certo é o que elas dizem que devemos fazer... (M3).

Esses dados apontam, mais uma vez, para a necessidade de rever a formação continuada dos professores, bem como para a realização de pesquisas que busquem compreender como essa formação vem ocorrendo nas escolas. Outra questão a destacar nos depoimentos, relacionada à formação continuada que recebiam, diz respeito aos materiais que chegam às escolas para regular o trabalho do professor e garantir uma unicidade em suas ações, o que pode ser verificado quando esses professores se referem ao programa "Ler e Escrever" ".

Está, está vinculado sim, elas cobram bastante o Ler e Escrever... Em cima daquilo que elas dão, elas cobram bastante... (M1).

Se, por um lado, nas ações de governo, dentro da lógica neoliberal, postula-se maior descentralização na implementação de políticas sociais e, dentre elas, nas políticas educacionais, o que se daria inclusive com incentivos à autonomia das instituiçóes escolares para o estabelecimento de parcerias, por outro, percebe-se o estabelecimento de açóes de extremo controle sobre as escolas como, por exemplo, a adoção de materiais tais como o programa "Ler e Escrever", que prescrevem as práticas docentes e regulam o currículo. Ao analisar as reformas educativas e suas repercussóes no trabalho docente, D. Oliveira (2008) destaca a instauração de controle técnico sobre os currículos por meio de processos estandartizados para sua implementação, o que reforça a separação entre concepção e execução no que diz respeito aos conteúdos escolares, cabendo ao professor uma tarefa eminentemente técnica. Para Barreto e Leher (2008), nessas reformas, o professor é visto como um cumpridor de tarefas

4. O programa "Ler e Escrever" foi implantado em 2008 na rede pública estadual paulista e dirigese às salas de aula do ciclo I do Ensino Fundamental, prevendo o envio de material de apoio ao professor, bem como de cadernos de atividades para os alunos. Disponível em: < http:// lereescrever.fde.sp.gov.br/site/>. Acesso em: 05 maio 2009. 
previamente estipuladas, devendo ser formado para saber acompanhar um guia didático. Assim, não é depositário de conhecimentos, mas portador de competências técnicas para o manejo de materiais, o que desqualifica seu trabalho.

Além disso, o fato de as ações de formação oferecidas aos professores centraremse no programa "Ler e Escrever" permite detectar a intenção dessa formação de atuar como correia de transmissão dos interesses da proposta oficial, promovendo a adesão pura e simples dos professores, indo na contramáo da possibilidade de desenvolvimento do pensamento autônomo. Os professores entrevistados possuíam muita clareza em relação à necessidade de uso do material relacionado ao programa "Ler e Escrever" na escola. Expressaram gostar do material, que lhes poupa o trabalho de preparo das aulas e de seleção de atividades para os alunos. As críticas feitas diziam respeito ao fato de o governo não ter enviado os cadernos de atividades dos alunos. Para eles, o material do "Ler e Escrever" não é uma amarra, mas um guia para suas açóes, propiciando-lhes economia de tempo e esforço .

De qualquer forma, foi possível detectar que o processo de racionalização tecnológica, que ocorre na sociedade industrial, apresenta-se na atividade educacional, levando o docente, que passa a submeter-se a essa racionalidade, à progressiva perda de autonomia em seu trabalho. O desempenho de sua funçáo em sala de aula reduz-se à aplicação de conteúdos estipulados e organizados previamente, segundo lógica relacionada à eficiência e à organização produtiva de saberes considerados relevantes ao aprendizado escolar, seguindo os princípios neoliberais, sobre os quais não há contestação por parte da escola.

\section{Condições materiais}

Os professores estabeleciam com a parceria uma relação contraditória, pois, se por um lado ela lhes proporcionava benefícios materiais bastante concretos, por outro queriam falar de algumas coisas que, de seu ponto de vista, não andavam bem. Essa tensão entre satisfação e insatisfação permeou toda a entrevista, com censuras e ponderaçóes entre os docentes. Nos dias em que ocorria a formaçáo dos professores, havia o fornecimento de lanche para eles, que também contavam com uma quota de xerox - num total de 300 cópias/mês -, além do serviço de limpeza prestado pela empresa parceira, bem como a reforma do prédio, açôes que trouxeram melhorias substantivas em suas condiçóes materiais de trabalho. Esses benefícios expressam maneiras pelas quais a iniciativa privada assume funções públicas, melhorando esse atendimento em alguns aspectos, e, por isso mesmo, sendo desejada, apesar de certos incômodos:

Então é isso, o que eu sinto é que essa parceria vem colaborar na higiene, é o que eu mais senti. Uma coisa que para mim faz muita diferença. Sala de aula... para mim é um alivio 
chegar e encontrar tudo limpo! Se eu chegar e encontrar tudo sujo...(M6).

Quando uma das professoras tentou discutir a parceria entre o público e o privado numa perspectiva política, criticando a presença da firma de limpeza na escola e questionando a ausência do Estado no cumprimento de uma obrigaçáo sua, qual seja, a de manter a escola limpa, ela sofreu forte resistência do grupo, mal conseguindo se posicionar. $\mathrm{O}$ argumento utilizado pelos colegas para defender a ação dos parceiros foi o de o governo não possuir dinheiro para a contratação do número de funcionários suficientes para manter limpa uma escola do tamanho daquela. Ou seja, falar sobre essas questóes causou incômodo aos professores que, entre outras questóes, preocupavam-se com a possibilidade de o serviço de limpeza ser interrompido.

\section{Relações entre a escola e a família}

Com relação à participação dos pais dos alunos na tomada de decisóes sobre a parceria, contrariamente ao estipulado, verificou-se que náo ocorria. Pelo que foi possível apreender nos depoimentos dos professores, de seu ponto de vista, os pais de seus alunos são ausentes, e não são traçados esforços para promover uma aproximação, seja pela escola, seja pela parceria. Tinham, inclusive, dúvidas sobre se essa aproximação seria, ou não, responsabilidade dos parceiros da escola:

Mas veja bem, a parceria não pode estar preocupada com a comunidade. Quem tem que estar é a escola... Ela não tem como ir atrás da comunidade. A escola que tem. E a escola até tem esse trabalho, mas está difícil, os pais daqui não se interessam pela vida escolar dos filhos... (M3).

De qualquer forma, para os professores, essa aproximação é um problema a ser enfrentado pela escola. Mas, segundo eles, os pais não estavam interessados nessa aproximação, uma vez que não se importavam com a escolarização de seus filhos, nem tampouco com sua educação. A questão da culpabilização dos pais pelo fracasso de seus filhos na escola, bem como a existência de uma visão preconceituosa ou estereotipada dos professores em relação a essas famílias tem sido destacada em diferentes estudos ${ }^{5}$. Nos depoimentos dos professores, evidencia-se que promover a aproximação dos pais com a escola náo é tarefa fácil de ser realizada e que essa percepção dos docentes em relaçấo às famílias continua sendo uma necessidade a ser discutida.

5. Sobre essa questão ver, entre outros, Patto (2000) e Marin (2002), que detectam dados divulgados nessa direção desde a década de 1950. 
Fica também explicitada a necessidade de realização de estudos que aprofundem a compreensão sobre as formas como essa aproximação tem sido, ou não, viabilizada por parcerias entre os setores público e privado, posto que promovê-la é objetivo das políticas implementadas pela Seesp. Trata-se de compreender se e como essa aproximação entre a família e a escola é promovida, uma vez que é uma relação conflituosa. De qualquer forma, explicitou-se tanto a inexistência de um trabalho integrado com a comunidade quanto a falta de discussóes entre os parceiros e os agentes escolares, seja com a direção, seja com os professores.

\section{Algumas considerações}

As açóes que incidem sobre as escolas públicas na atualidade e, dentre elas, a realização de parcerias entre o setor público e o privado, inserem-se em conjunto de proposições que expressam os novos rumos tomados pelas açóes políticas educacionais, que dizem respeito à adoção do ideário neoliberal, especialmente em relação à necessidade de busca de mecanismos mais eficientes e modernos para a solução de problemas visando à qualidade da educação. $\mathrm{Na}$ implantação dessas açóes, o trabalho do professor vem sendo destacado como aspecto chave para a melhoria da educação e para a promoção da qualidade do ensino. Nesse sentido, torna-se relevante a compreensão das formas como tais ações são desenvolvidas nas escolas, e, especialmente, como incidem sobre o trabalho docente. Torna-se relevante também questionar a própria ideia de qualidade nelas implicada.

Em Sáo Paulo, a realização de parcerias entre os setores público e privado visando à qualidade do ensino é ação política pública adotada pela Seesp, a qual incide diretamente sobre o trabalho dos professores. A entrada na escola para a realização desta pesquisa, com o objetivo de verificar os efeitos dessas parcerias na dinâmica escolar e, mais especificamente, no trabalho do professor, revelou, por um lado, parcela da intensificação do seu trabalho, uma vez que essas açóes o sobrecarregavam em suas tarefas cotidianas; e, por outro, a perda crescente de sua condiçấo de decisão, pois os professores não foram consultados sobre as açóes a serem desenvolvidas pelos parceiros.

A pesquisa revelou, também, que a formação continuada - uma das ações realizadas pela parceria na escola - necessita ser repensada a fim de, por um lado, incentivar e promover o trabalho em equipe e a valorização de seus saberes da prática e, por outro, o desenvolvimento do potencial intelectual e profissional dos professores. Pelo que se viu, nas ações de formação estabelecidas, o trabalho em equipe não era favorecido, seja pela falta de participaçấo na tomada de decisóes, seja pela forma como os horários de formação eram utilizados, ou mesmo pelo conteúdo dessas ações de formação. O desenvolvimento do potencial intelectual dos professores viu-se comprometido, uma vez que não favoreceu ampliação de sua 
compreensão em relação à escola como instituição social e aos processos educativos nela desencadeados. Além disso, a chegada às escolas de materiais prontos para serem usados pelos professores em suas aulas, cuja utilização dava o tom dessas formaçôes, também aponta para a diminuição da condição de decisão e opção dos professores, um aspecto central de seu trabalho. Este momento da pesquisa aponta para a necessidade de realização de estudos aprofundados sobre a chegada desses materiais às escolas e também para os processos de formação continuada aos quais os professores são submetidos.

Destaca-se que não apenas esses potenciais do professor se viram comprometidos, mas a própria condição de autonomia da escola, inviabilizando aspectos destacados como fundamentais em várias açôes políticas na última década, como, por exemplo, a elaboração de plano escolar e de projeto pedagógico específicos. As açóes estabelecidas pela parceria eram decididas à revelia da equipe escolar, além de serem descontínuas, sendo possível questionar seus propósitos educativos.

Foi possível evidenciar que a entrada da iniciativa privada nas escolas por meio de açóes estabelecidas por parcerias, portanto, contribui para a redução da esfera de atuação estatal, uma vez que a empresa parceira assume a oferta de serviços que são de responsabilidade do Estado. A iniciativa privada propóe mecanismos mais ágeis para atender algumas demandas da escola, e por isso mesmo é desejada pelos agentes escolares. No entanto, essas demandas não são debatidas e estabelecidas coletivamente. Assim, contribui para a disseminação do ideário neoliberal que propôe um Estado mínimo, ao mesmo tempo que funciona como mecanismo de controle e de regulação sobre as açóes escolares e, dentre estas, o trabalho do professor. Ao descentralizar e flexibilizar a oferta de aspectos do serviço público nas escolas, como a limpeza ou a reforma do prédio, não contribui para a potencialização dessa instituição, seja no que diz respeito à gestão escolar, seja no que diz respeito ao trabalho do professor, colaborando para a contradição em relação à proposta.

Para além de questionar os efeitos produzidos por essas açóes no trabalho do professor, importa atentar para aspectos da própria dinâmica escolar a partir da interferência do setor privado. Faz-se necessário explicitar as formas pelas quais o espaço público vem se tornando um espaço privado, uma vez que a prestação de uma série de serviços é assumida pela empresa parceira, que se sente dona desse espaço, toma decisóes à revelia dos agentes escolares e se incomoda com a presença de pesquisadores na escola. Além de serem impostas e descontínuas - o que já é bastante problemático - faz-se necessário questionar qual a lógica implicada nessas açôes, ou seja, se de fato são açóes para a valorização do ensino, e o que é que se está entendendo por ensino de qualidade. Para quem essas ações trazem resultados? Quem avalia esses resultados?

A realização desta etapa da pesquisa aponta para a necessidade de explicitar essas questôes, pois se trata da defesa do Estado e de suas funçôes universais públicas, 
ou seja, de garantia do caráter gratuito, uniforme e geral do fornecimento de bens e serviços sociais e do amplo acesso dos beneficiários a esses serviços.

\section{Referências bibliográficas}

BARRETO, R. G.; LEHER, R. Trabajo docente y reformas neoliberais. In: OLIVEIRA, D. A. (Org.). Politicas educativas y trabajo docente en América Latina. Lima- Peru: Fondo Editoria UCH, 2008. p. 53-86.

BOURDIEU, P. Contrafogos: táticas para enfrentar a invasão neoliberal. RJ: Jorge Zahar, 1998. $151 \mathrm{p}$.

DRAIBE, S. As políticas sociais e o neoliberalismo: reflexóes suscitadas pelas experiências latino-americanas. Revista da USP - Dossiê Liberalismo/ Neoliberalismo, São Paulo, n. 17, p. 86-101, mar./ maio 1993.

GENTILI, P. As políticas educacionais no contexto do neoliberalismo: os significados da privatização no campo educacional. In: OLIVEIRA, M. N. de (Org.). As políticas educacionais no contexto da globalização. Ilhéus, BA: Editus, 1999. p. 105-130.

MARIN, A. J. Formação de professores e culturas escolares: velhos e novos desafios. In: GARCIA, W. G. Pedagogia cidadã - cadernos de formação. São Paulo: Páginas e Letras, 2002. p. 128-136.

OLIVEIRA, C. A terceirização no ensino municipal e o trabalho docente. In: EGGERT, E. et al. (Org.). Trajetórias e processos de ensinar e aprender: lugares, memórias, culturas. In: ENDIPE, 14., 2008, Porto Alegre. Anais... Porto Alegre: Edipucrs, 2008. p.134-150.

OLIVEIRA, D. A. Las reformas educativas y sus repercusiones en el trabajo docente. In: OLIVEIRA, D. A. (Org.) Políticas educativas y trabajo docente en América Latina. LimaPeru: Fondo Editoria UCH, 2008. p. 17-52.

PATTO, M. H. S. A produção do fracasso escolar. 2. ed. São Paulo: Casa do Psicólogo, 2000.

PERONI, V. M. V. O público e o privado na gestão e financiamento de sistemas educacionais públicos: um estudo dos programas da Rede vencer, coordenado pelo Instituto Ayrton Senna. In: SIMPÓSIO BRASILEIRO DE POLÍTICAS E ADMINISTRAÇÃO DA EDUCAÇÃO, 23., 2007, Porto Alegre, RS. Anais... Porto Alegre, 2007. Disponível em: <http://www.isecure.com.br/anpae/>. Acesso em: maio 2009.

Recebido em 09 de dezembro de 2010 e aprovado em 21 de julho de 2011. 